\title{
Potential risk of infection of pathogenic fungi to legumes (Fabales) and possibilities of their control
}

\author{
Zagrożenie roślin strączkowych (bobowych) \\ przez grzyby chorobotwórcze i możliwości ich zwalczania
}

\author{
Joanna Horoszkiewicz-Janka, Ewa Jajor, Marek Korbas
}

\section{Summary}

The aim of the study was to determine the present or predicted risk posed by pathogenic fungi in cultivation of legumes: lupine, pea, horse bean, soybean, and the review of the range of substances substances available in Poland from 2000 to 2013 , for control of the diseases in these crops. The Plant Protection Recommendations served as resource material for analysis of fungicides registered for protection of Fabales, while assessment of risk of the diseases was carried out on the basis of the authors' observations and literature reports. The study showed significant limitations in the possibilities of disease control with the use of fungicides in legumes in the last few years.

Key words: leguminous crops, diseases, active substances

\section{Streszczenie}

Celem badań było określenie obecnego oraz prognozowanego zagrożenia przez grzyby chorobotwórcze upraw roślin bobowych: łubinu, grochu, bobiku i soi oraz przegląd asortymentu dostępnych w Polsce od 2000 do 2013 roku substancji czynnych przeznaczonych do zwalczania chorób w tych uprawach. Jako materiał źródłowy do analizy zarejestrowanych w roślinach bobowych fungicydów posłużyły Zalecenia Ochrony Roślin, natomiast ocenę zagrożenia występowania chorób wykonano na podstawie obserwacji własnych oraz doniesień literaturowych. Opracowanie wykazało istotne ograniczenie w ostatnich latach możliwości zwalczania chorób roślin strączkowych przy użyciu fungicydów.

Słowa kluczowe: rośliny strączkowe, choroby, substancje czynne

Instytut Ochrony Roślin - Państwowy Instytut Badawczy

Zakład Mikologii

Władysława Węgorka 20, 60-318 Poznań

j.horoszkiewicz@iorpib.poznan.pl 


\section{Wstęp / Introduction}

Wysokość strat powstających w produkcji strączkowych (bobowych) spowodowanych występowaniem chorób szacuje się średnio na $15 \%$, chociaż niekiedy są one znacznie wyższe i wynosić mogą 70-80\%. Rośliny te narażone są na porażenie przez cały okres wegetacji - od kiełkowania do końca formowania się strąków i wypełniania nasion. Początek pojawu oraz nasilenie występowania chorób powodowanych przez grzyby bywają różne w poszczególnych sezonach wegetacji, a zależy to od uprawianego gatunku, a nawet odmiany. Rośliny strączkowe $\mathrm{w}$ okresie kwitnienia są szczególnie narażone na porażenie przez grzyby chorobotwórcze.

Celem pracy było określenie obecnego i prognozowanego zagrożenia ze strony sprawców chorób dla roślin strączkowych. Ze względu na konieczność stosowania chemicznej ochrony, przeanalizowano zmiany $\mathrm{w}$ asortymencie dostępnych w Polsce substancji czynnych (s.cz.) do zwalczania ważnych patogenów tych gatunków roślin.

\section{Materiały i metody / Materials and methods}

Materiał badań stanowiły wybrane gatunki roślin strączkowych: bobik, groch siewny i jadalny, soja oraz łubin biały, wąskolistny i żółty. Na podstawie doświadczeń własnych oraz informacji dostępnych w literaturze polskiej i europejskiej, określono obecne i prognozowane znaczenie ważniejszych patogenów dla tych gatunków (Fiedorow i wsp. 2008; Krawczyk i Mrówczyński 2012; Korbas i Horoszkiewicz-Janka 2013). Zmiany w asortymencie dostępnych w Polsce s.cz. przeanalizowano na podstawie Zaleceń Ochrony Roślin wydanych w latach 2000-2013 oraz etykiet fungicydów zarejestrowanych w Polsce, w tych uprawach (Etykiety fungicydów 2013; Rejestr środków ochrony roślin 2012-2013). W pracy poszukiwano przyczyn zmian liczby zarejestrowanych s.cz. oraz alternatywnych możliwości użycia s.cz. do chemicznego zwalczania patogenów roślin strączkowych lub innych metod ich ograniczania. Stosowanie wolnego od patogenów materiału siewnego może być jednym ze sposobów zmniejszania ich występowania na plantacjach, ale takie działanie nie powoduje utrzymania zdrowotności roślin przez cały sezon wegetacyjny. Możliwość walki chemicznej daje szansę na ochronę roślin strączkowych przed porażeniem przez ważnych sprawców chorób.

\section{Wyniki i dyskusja / Results and discussion}

Gatunki roślin strączkowych: groch, bobik, łubin i soja, należą do grupy roślin rolniczych i przemysłowych, które nie są powszechnie uprawiane na terytorium Rzeczypospolitej Polskiej (Rozporządzenie Ministra Rolnictwa i Rozwoju Wsi z dnia 22 maja 2013 roku). W uprawach tych wiele grzybów chorobotwórczych powoduje zagrożenie o znaczeniu gospodarczym. Niektóre z patogenów mogą powodować epidemie na terenie całego kraju i są powodem dyskwalifikacji plantacji nasiennych (np. antraknoza łubinu). Inne natomiast pojawiają się incydentalnie i nie mają z reguły wpływu na plon, ale gdy wystąpią na plantacji jednocześnie, też mogą być powodem strat. $\mathrm{W}$ tabeli 1 . zestawiono choroby występujące $\mathrm{w}$ uprawie bobiku, grochu, łubinu i soi oraz podano ich znaczenie (Frencel i wsp. 1998; Jańczak i wsp. 2001; Kryczyński i Weber 2011). We wszystkich wymienionych uprawach, poza soją, występują sprawcy chorób, których znaczenie gospodarcze jest istotne. Ryzyko obniżki potencjalnych plonów i pogorszenia ich jakości spowodowane wystạpieniem chorób dla każdej z upraw jest duże. Zasadniczo $\mathrm{w}$ równym stopniu każda uprawa narażona jest w początkowych fazach rozwoju na porażenie przez grzyby powodujące zgorzele siewek. Zwalczanie sprawców zgorzeli siewek wykonuje się przez chemiczne zaprawianie materiału siewnego. Pozostałych sprawców chorób można ograniczać przez zabiegi opryskiwania $\mathrm{w}$ trakcie wegetacji, jednak liczba fungicydów zarejestrowanych $\mathrm{w}$ ostatnich latach do stosowania w omawianej grupie roślin zmalała w porównaniu do liczby na początku 21 . wieku. W latach 2000-2005 następował systematyczny wzrost ilości s.cz. (tab. 2, rys. 1). Największa liczba zarejestrowanych s.cz. (20) była na przełomie lat 2004-2005. Od 2006 roku liczba zarejestrowanych s.cz. do chwili obecnej drastycznie zmalała. Obecnie do ochrony omawianych roślin strączkowych dopuszczonych jest 7 s.cz. Do ochrony tubinu i grochu zarejestrowane są dwie s.cz. (tiuram i karboksyna), które zawarte są w zaprawie Vitavax 200 FS. Brakuje natomiast fungicydów zarejestrowanych do ochrony łubinu przed grzybami chorobotwórczymi w trakcie wegetacji. W uprawie, zwłaszcza łubinu żółtego, duże niebezpieczeństwo stanowi antraknoza. Dotyczy to szczególnie lat o podwyższonej temperaturze powietrza i wilgotności w okresie kwitnienia (Agrios 2005). Jeżeli choroba ta pojawi się, zwłaszcza $\mathrm{w}$ okresie kwitnienia, wymaga zwalczania, ponieważ powoduje zamieranie tworzących się strąków. Do zwalczania tej groźnej choroby zarejestrowanych było kilka fungicydów, jednak niewielkie zainteresowanie producentów środków ochrony roślin (ś.o.r.) uprawami małoobszarowymi oraz brak dostatecznej liczby badań w tych uprawach spowodowały, że nie zostały one uwzględnione $\mathrm{w}$ zakresie nowej etykiety.

W przypadku grochu, do opryskiwania roślin, zarejestrowanych jest najwięcej s.cz., tzn. 4. Wynika to prawdopodobnie $\mathrm{z}$ przeznaczenia grochu na cele jadalne, $\mathrm{w}$ tym konserwowe. Fungicydy te pochodzą $\mathrm{z}$ różnych grup chemicznych takich, jak: strobiluryny (azoksystrobina), ftalany (chlorotalonil), anilinopirymidyny (cyprodynil), fenylopirole (fludioksonil). W sumie wymienione powyżej s.cz. wchodzą w skład 3 fungicydów. Liczba ta może być niewystarczająca, zwłaszcza na plantacjach, na których fungicydy są często stosowane, ze względu na możliwość uodpornienia się grzybów na aplikowane s.cz. Niestety brakuje s.cz. zarejestrowanych do stosowania $\mathrm{w}$ uprawie bobiku i soi. Dotyczy to s.cz. do zaprawiania nasion oraz fungicydów do opryskiwania roślin w trakcie wegetacji.

Producenci rolni mają możliwość ograniczania sprawców chorób roślin strączkowych głównie przy użyciu metod niechemicznych (agrotechnika lub uprawa odmian o większej odporności). Podstawowe znaczenie w metodzie agrotechnicznej mają: właściwy wybór przedplonu 
Tabela 1. Znaczenie ważniejszych chorób w wybranych gatunkach roślin bobowych

Table 1. Significance of major diseases in cultivation of selected species of Fabales

\begin{tabular}{|c|c|c|c|c|}
\hline $\begin{array}{l}\text { Gatunek } \\
\text { Species }\end{array}$ & $\begin{array}{l}\text { Choroba } \\
\text { Disease }\end{array}$ & $\begin{array}{c}\text { Sprawca(y) } \\
\text { Causal agent(s) }\end{array}$ & $\begin{array}{l}\text { Znaczenie obecnie } \\
\text { Present status }\end{array}$ & $\begin{array}{c}\text { Znaczenie } \\
\text { w przyszłości } \\
\text { Future status }\end{array}$ \\
\hline 1 & 2 & 3 & 4 & 5 \\
\hline \multirow[t]{2}{*}{$\begin{array}{l}\text { Różne } \\
\text { gatunki roślin bobowych } \\
\text { Different species } \\
\text { of Fabales }\end{array}$} & $\begin{array}{l}\text { zgorzel siewek } \\
\text { root rots }\end{array}$ & $\begin{array}{c}\text { Rhizoctonia solani, } \\
\text { Ascochyta sp., } \\
\text { Colletotrichum } \\
\text { gloeosporioides, } \\
\text { Pythium spp., } \\
\text { Fusarium spp., } \\
\text { Alternaria spp. } \\
\text { i inne - and others }\end{array}$ & +++ & ++ \\
\hline & $\begin{array}{l}\text { zgnilizna twardzikowa } \\
\text { Sclerotinia stem rot }\end{array}$ & Sclerotinia sclerotiorum & ++ & ++ \\
\hline \multirow{5}{*}{$\begin{array}{l}\text { Bobik } \\
\text { Horse bean }\end{array}$} & $\begin{array}{l}\text { więdnięcie i sucha } \\
\text { zgnilizna korzeni bobiku } \\
\text { Fusarium wilt } \\
\text { and root rot }\end{array}$ & $\begin{array}{c}\text { Fusarium oxysporum, } \\
\text { F. solani, } \\
\text { F. avenaceum, } \\
\text { Rhizoctonia solani }\end{array}$ & +++ & ++ \\
\hline & $\begin{array}{c}\text { askochytoza bobiku } \\
\text { Ascochyta leaf } \\
\text { and pod spot }\end{array}$ & Ascochyta fabae & ++ & + \\
\hline & $\begin{array}{c}\text { czekoladowa plamistość } \\
\text { bobiku } \\
\text { black spot }\end{array}$ & $\begin{array}{l}\text { Botrytis fabae, } \\
\text { B. cinera }\end{array}$ & +++ & ++ \\
\hline & $\begin{array}{c}\text { rdza bobiku } \\
\text { horse bean rust }\end{array}$ & Uromyces fabae & ++ & ++ \\
\hline & $\begin{array}{c}\text { mączniak prawdziwy } \\
\text { powdery mildew }\end{array}$ & Erysiphe fabae & + & + \\
\hline \multirow{6}{*}{$\begin{array}{l}\text { Groch } \\
\text { Pea }\end{array}$} & $\begin{array}{c}\text { zgorzelowa plamistość } \\
\text { grochu } \\
\text { (askochytoza grochu) } \\
\text { Ascochyta leaf } \\
\text { and pod spot }\end{array}$ & $\begin{array}{c}\text { Ascochyta pinodes, } \\
\text { A.pisi, } \\
\text { Phoma pinodella }\end{array}$ & ++ & + \\
\hline & $\begin{array}{c}\text { rdza grochu } \\
\text { pea rust }\end{array}$ & Uromyces pisi & ++ & + \\
\hline & $\begin{array}{c}\text { mączniak prawdziwy } \\
\text { powdery mildew }\end{array}$ & Erysiphe pisi & + & + \\
\hline & $\begin{array}{l}\text { mączniak rzekomy } \\
\text { downy mildew }\end{array}$ & Peronospora pisi & ++ & + \\
\hline & $\begin{array}{c}\text { szara pleśń } \\
\text { grey mold }\end{array}$ & Botrytis cinerea & ++ & + \\
\hline & $\begin{array}{l}\text { fuzaryjne więdnięcie } \\
\text { grochu i fuzaryjna } \\
\text { zgorzel grochu } \\
\text { Fusarium wilt and rot }\end{array}$ & $\begin{array}{c}\text { Fusarium oxysporum, } \\
\text { F. solani, } \\
\text { Fusarium spp. }\end{array}$ & +++ & ++ \\
\hline \multirow{3}{*}{$\begin{array}{l}\text { Łubin biały, wąskolistny } \\
\text { i żółty } \\
\text { White, blue and yellow } \\
\text { lupine }\end{array}$} & $\begin{array}{l}\text { antraknoza } \\
\text { anthracnose }\end{array}$ & $\begin{array}{c}\text { Glomerella cingulata } \\
\text { (st. konid. - conidial stage } \\
\text { Colletotrichum } \\
\text { gloeosporioides) }\end{array}$ & +++ & ++ \\
\hline & $\begin{array}{c}\text { fuzaryjna zgorzel } \\
\text { i więdnięcie fuzaryjne } \\
\text { łubinu } \\
\text { Fusarium rot and wilt }\end{array}$ & $\begin{array}{c}\text { Fusarium oxysporum } \\
\text { f. sp. lupini, } \\
\text { F. avenaceum, } \\
\text { F. graminearum, } \\
\text { F. bulbigenum } \\
\end{array}$ & +++ & + \\
\hline & $\begin{array}{l}\text { opadzina liści łubinu } \\
\text { (szara plamistość liści) } \\
\text { leaf spot }\end{array}$ & $\begin{array}{l}\text { Pleospora herbarum } \\
\text { (st. kon. - conidial stage } \\
\text { Stemhylium botryosum) }\end{array}$ & ++ & + \\
\hline
\end{tabular}




\begin{tabular}{|c|c|c|c|c|}
\hline 1 & 2 & 3 & 4 & 5 \\
\hline \multirow{4}{*}{$\begin{array}{l}\text { Soja } \\
\text { Soybean }\end{array}$} & $\begin{array}{l}\text { mączniak rzekomy } \\
\text { downy mildew }\end{array}$ & Peronospora manshurica & ++ & + \\
\hline & $\begin{array}{l}\text { fuzarioza korzeni } \\
\text { i siewek } \\
\text { Fusarium root rot } \\
\text { and seedling blight }\end{array}$ & $\begin{array}{c}\text { Fusarium oxysporum, } \\
\text { F. solani, } \\
\text { F. culmorum }\end{array}$ & ++ & ++ \\
\hline & $\begin{array}{c}\text { askochytoza soi } \\
\text { Ascochyta leaf and pod } \\
\text { spot }\end{array}$ & Ascochyta sojaecola & + & + \\
\hline & $\begin{array}{c}\text { rdza soi } \\
\text { soybean rust }\end{array}$ & Phakopsora pachyrhizi & + & ++ \\
\hline
\end{tabular}

+++ choroba o dużym znaczeniu - disease of major importance

++ choroba o średnim znaczeniu - disease of medium importance

+ choroba występująca sporadycznie (lokalnie) - disease of local importance

Tabela 2. Substancje czynne fungicydów zarejestrowanych do ochrony bobiku, grochu, łubinu i soi w latach 2000-2013

Table 2. Active substances of fungicides registered for protection of horse bean, pea, lupine and soybean in the years 2000-2013

\begin{tabular}{|c|c|c|c|c|c|c|c|}
\hline \multirow{2}{*}{$\begin{array}{l}\text { Substancja czynna } \\
\text { Active substance }\end{array}$} & \multicolumn{7}{|c|}{ Lata - Years } \\
\hline & $2000-2001$ & $2002-2003$ & $2004-2005$ & $2006-2007$ & $2008-2009$ & $2010-2011$ & $2012-2013$ \\
\hline Azoxystrobin & - & - & 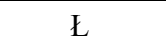 & 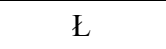 & 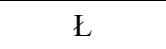 & $\mathrm{G}$ & $\mathrm{G}$ \\
\hline Benomyl & $\mathrm{B}$ & $\mathrm{B}$ & $\mathrm{B}$ & - & - & - & - \\
\hline Bitertanol & $\mathrm{G}, \mathrm{t}$ & $\mathrm{E}$ & $G, €$ & - & - & - & - \\
\hline Captan & $\mathrm{G}$ & $\mathrm{G}$ & $\mathrm{G}$ & $\mathrm{G}$ & G & - & - \\
\hline Carbendazim & $\mathrm{B}, \mathrm{G}, \mathrm{L}$ & $\mathrm{B}, \mathrm{G}, \mathrm{L}$ & $\mathrm{B}, \mathrm{G}, \mathrm{E}$ & $\mathrm{B}, \mathrm{G}, \mathrm{L}$ & - & - & - \\
\hline Carboxin & $\mathrm{B}, \mathrm{G}, \mathrm{S}$ & $\mathrm{B}, \mathrm{G}, \mathrm{S}$ & $\mathrm{B}, \mathrm{G}, \mathrm{\ell}, \mathrm{S}$ & $\mathrm{B}, \mathrm{G}, \mathrm{\ell}, \mathrm{S}$ & $\mathrm{B}, \mathrm{G}, \mathrm{\ell}, \mathrm{S}$ & $\mathrm{B}, \mathrm{G}, \mathrm{t}$ & $\mathrm{G}, \mathrm{\iota}$ \\
\hline Chlorothalonil & $\mathrm{B}, \mathrm{G}, \mathrm{t}$ & $\mathrm{B}, \mathrm{G}, \mathrm{L}$ & $\mathrm{B}, \mathrm{G}, \mathrm{E}$ & $\mathrm{B}, \mathrm{G}, \mathrm{t}$ & $\mathrm{B}, \mathrm{G}, \mathrm{E}$ & $\mathrm{B}, \mathrm{G}, \mathrm{L}$ & $G$ \\
\hline $\begin{array}{l}\text { Chlorothalonil } \\
\text { with zinc }\end{array}$ & G & $\mathrm{G}, \mathrm{L}$ & $\mathrm{G}, \mathrm{\iota}$ & $\mathrm{G}, \mathrm{\iota}$ & - & - & - \\
\hline Copper & - & - & - & $\mathrm{G}$ & - & - & - \\
\hline Cyprodinil & - & - & - & - & - & G & G \\
\hline Dichlofluanid & B & $\mathrm{B}$ & $\mathrm{B}$ & - & - & - & - \\
\hline Dinocap & G & G & G & - & - & - & - \\
\hline Fludioxonil & - & - & - & - & - & $\mathrm{G}$ & $\mathrm{G}$ \\
\hline Flusilazole & - & - & $\mathrm{B}$ & $\mathrm{B}$ & - & - & - \\
\hline Fuberidazole & $\mathrm{G}, \mathrm{E}$ & $E$ & $\mathrm{G}, \mathrm{E}$ & - & - & - & - \\
\hline Grapefruit extract & - & - & - & - & G & G & - \\
\hline Iprodione & $\mathrm{B}$ & $\mathrm{B}$ & $\mathrm{B}$ & $\mathrm{B}$ & $\mathrm{B}$ & $\mathrm{B}$ & $\mathrm{B}$ \\
\hline Mancozeb & $\mathrm{B}, \mathrm{G}$ & $\mathrm{B}, \mathrm{G}$ & $\mathrm{B}, \mathrm{G}$ & $\mathrm{B}, \mathrm{G}$ & $\mathrm{B}, \mathrm{G}$ & $\mathrm{B}, \mathrm{G}$ & - \\
\hline Metalaxyl & $\mathrm{G}$ & - & - & - & - & - & - \\
\hline Prochloraz & $\mathrm{B}$ & $\mathrm{B}$ & $\mathrm{B}$ & $\mathrm{B}$ & $\mathrm{B}$ & $\mathrm{B}$ & - \\
\hline Procymidone & $\mathrm{B}$ & $\mathrm{B}$ & $\mathrm{B}$ & $\mathrm{B}$ & - & - & - \\
\hline Sulphur & G & $\mathrm{B}, \mathrm{G}, \mathrm{t}$ & $\mathrm{B}, \mathrm{G}, \mathrm{t}$ & $\mathrm{B}, \mathrm{G}, \mathrm{t}$ & $\mathrm{B}, \mathrm{G}, \mathrm{L}$ & $\mathrm{B}, \mathrm{G}, \mathrm{t}$ & - \\
\hline Thiophanate-methyl & $\mathrm{B}, \mathrm{G}$ & $\mathrm{B}, \mathrm{G}$ & $\mathrm{B}$ & $\mathrm{B}, \mathrm{G}$ & $\mathrm{B}, \mathrm{G}$ & - & - \\
\hline Thiram & $\mathrm{B}, \mathrm{G}, \mathrm{\ell}, \mathrm{S}$ & $\mathrm{B}, \mathrm{G}, \mathrm{\ell}, \mathrm{S}$ & $\mathrm{B}, \mathrm{G}, \mathrm{\ell}, \mathrm{S}$ & $\mathrm{B}, \mathrm{G}, \mathrm{E}, \mathrm{S}$ & $\mathrm{B}, \mathrm{G}, \mathrm{t}, \mathrm{S}$ & $\mathrm{B}, \mathrm{G}, \mathrm{\ell}$ & $\mathrm{G}, \mathrm{\ell}$ \\
\hline Vinclozolin & $\mathrm{B}$ & $\mathrm{B}$ & $\mathrm{B}$ & $\mathrm{B}$ & - & - & - \\
\hline
\end{tabular}

B - bobik - faba bean, G - groch - pea, $€$ - łubin - lupin, S - soja - soybean

i stanowiska, staranne przygotowanie roli, optymalne dla danych warunków nawożenie, poprawne oraz terminowe wykonanie siewu, do którego używany jest zdrowy, kwali- fikowany materiał nasienny oraz prowadzenie odpowiednich prac pielęgnacyjnych (Krawczyk i Mrówczyński 2012). 


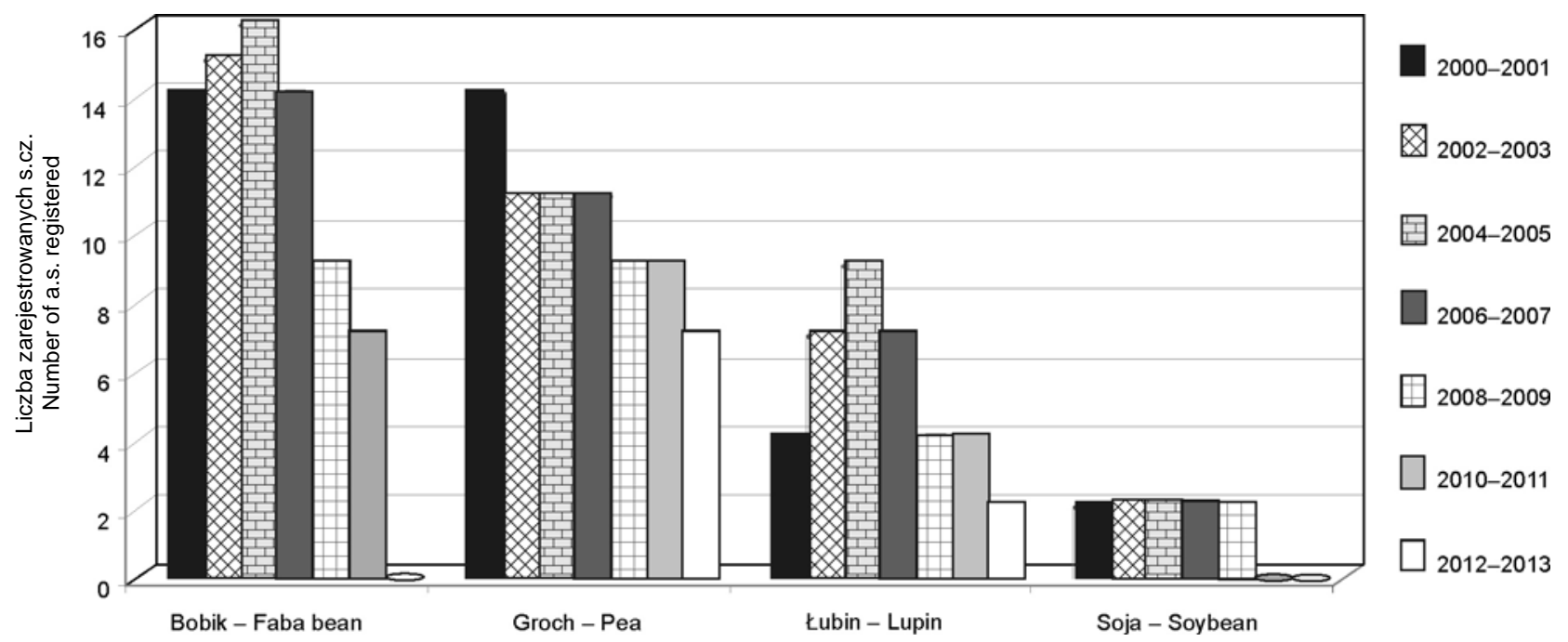

Rys. 1. Liczba substancji czynnych zarejestrowanych do ochrony wybranych gatunków roślin strączkowych w latach 2000-2013 Fig. 1. Number of active substances registered for protection of selected species of leguminous plants in the years 2000-2013

W opracowaniu Matyjaszczyk (2011) wykazano wzrost liczby zarejestrowanych ś.o.r. na przełomie lat 2007/2008, jednak dostępne środki dotyczyły głównie wielkoobszarowych upraw rolniczych. Potwierdzają to przeprowadzone analizy własne, w których wykazano zmniejszenie liczby s.cz. od 2006 roku.

$\mathrm{W}$ ostatnich latach jedną $\mathrm{z}$ przyczyn zmian $\mathrm{w}$ rejestracji ś.o.r. w Polsce, jest przyjęcie przez nasz kraj unijnych aktów prawnych (Matyjaszczyk 2011; Stajszczak 2011). Po przystapieniu do Unii Europejskiej miał miejsce spadek liczby zarejestrowanych ś.o.r. (Matyjaszczyk 2009). Było to związane z ograniczaniem dostępnych s.cz. oraz zakresów etykiet środków ponownie rejestrowanych. Zaostrzone również zostały wymagania $\mathrm{w}$ stosunku do wcześniej zarejestrowanych i nowo rejestrowanych s.cz. dotyczące ich toksyczności dla ludzi i środowiska.

W innych krajach, np. we Francji i Niemczech, o dużej powierzchni zasiewów roślin strączkowych, istnieje możliwość stosowania środków grzybobójczych. Substancje czynne, które występują w tych fungicydach są w Polsce zarejestrowane, ale zalecane są do zwalczania patogenów, np. w zbożach, rzepaku i burakach (Thomas i Sweetingham 2003). Istnieje potencjalna możliwość ich rejestracji, co może ułatwiać walkę $\mathrm{z}$ chorobami, które wysteppuja w roślinach strączkowych (np. krótkoterminowo - „skrócona procedura"). Dodatkowym rozwiązaniem może być rejestracja fungicydów na podstawie rozszerzenia zakresu zezwoleń na zastosowania małoobszarowe (Rozporządzenie Ministra Rolnictwa i Rozwoju Wsi z dnia 22 maja 2013 roku). Jego celem jest poszerzenie zakresu zezwolenia na wprowadzenie do obrotu ś.o.r., który uzyskał już zezwolenie w danym państwie członkowskim. Wystapić o takie zezwolenie mogą: podmioty urzędowe lub naukowe zajmujące się sprawami rolnictwa, branżowe organizacje rolnicze lub użytkownicy profesjonalni. Zezwolenia te są jedną z możliwości zabezpieczenia roślin przed stratami w plonach powodowanymi przez grzyby chorobotwórcze. Praktyka rolnicza wskazuje jednak, że bez możliwości zastosowania fungicydów, skuteczne zwalczanie tych chorób jest trudne (Horoszkiewicz-Janka i wsp. 2012).

Istotnym problemem, poza zmniejszeniem liczby środków, jest również cena środka. Matyjaszczyk (2007) zaznacza, że ochrona z zastosowaniem środków obecnie dostępnych na rynku, niejednokrotnie wymaga wyższych nakładów finansowych niż zabiegi wykonywane preparatami, które zostały wycofane.

\section{Wnioski / Conclusions}

1. Możliwości zwalczania chorób przy użyciu fungicydów w roślinach strączkowych zostały w ostatnim czasie istotnie ograniczone, co skutkuje obniżką plonów tych roślin z powodu obecności patogenów.

2. W uprawie grochu zarejestrowane są fungicydy do zaprawiania oraz opryskiwania roślin w trakcie wegetacji.

3. Do ochrony tubinów zarejestrowana jest jedynie zaprawa nasienna, co przy braku fungicydów do stosowania w okresie wegetacji nie daje możliwości odpowiedniej ich ochrony przez cały sezon wegetacyjny.

4. W uprawach bobiku i soi z powodu braku zarejestrowanych fungicydów nie ma możliwości chemicznej ochrony, co może być powodem zmniejszania powierzchni lub nie podejmowania uprawy tych gatunków roślin.

\section{Literatura / References}


Fiedorow Z., Gołębniak B., Weber Z. 2008. Choroby roślin rolniczych. Wydawnictwo AR, Poznań, 208 ss.

Frencel I., Wiatr K., Panasik J. 1998. Problem antraknozy łubinów w Polsce w świetle badań 1995-1997. [Problem of anthracnose on lupins in Poland in the years 1995-1997]. Prog. Plant Prot./Post. Ochr. Roślin 38 (1): 238-245.

Horoszkiewicz-Janka J., Jajor E., Korbas M. 2012. Wykorzystanie biopreparatów do zaprawiania nasion roślin strączkowych (bobowe). J. Res. Appl. Agric. Engin. 57 (3): 162-166.

Jańczak C., Horoszkiewicz J., Filoda G., Czerwińska A. 2001. Choroby grzybowe łubinu wąskolistnego i ich zwalczanie. [Fungal diseases of narrow-leafed lupin and their control]. Prog. Plant Prot./Post. Ochr. Roślin 41 (2): 714-717.

Korbas M., Horoszkiewicz-Janka J. 2013. Grzyby strączkom nie odpuszczą. Dodatek Top Agrar Polska Strączkowe: 50-55.

Krawczyk R., Mrówczyński M. (red.). 2012. Metodyka integrowanej ochrony łubinu wąskolistnego, żółtego i białego dla doradców. Inst. Ochr. Roślin - PIB, Poznań, 132 ss.

Kryczyński S., Weber Z. (red.). 2011. Choroby roślin uprawnych. t. 2, PWRiL, Poznań, 464 ss.

Matyjaszczyk E. 2007. Stan aktualny dopuszczania środków ochrony roślin do stosowania w rolnictwie konwencjonalnym i ekologicznym w Polsce. Inst. Ochr. Roślin, Poznań, 338 ss.

Matyjaszczyk E. 2009. Koszty rejestracji środków ochrony roślin w Polsce. [Costs of plant protection products' in Poland]. Prog. Plant Prot./Post. Ochr. Roślin 49 (2): 500-507.

Matyjaszczyk E. 2011. Rejestracja środków ochrony roślin w Polsce - historia, stan obecny i przyszłość. [Registration of plant protection products in Poland - the history, present state and future]. Prog. Plant Prot./Post. Ochr. Roślin 51 (1): $77-87$.

Rejestr środków ochrony roślin dopuszczonych do obrotu zezwoleniem Ministra Rolnictwa i Rozwoju Wsi (2012-2013). http://www.minrol.gov.pl/pol/Informacje-branzowe/Ochrona-roslin, dostęp: 02.01.2012-23.07.2013.

Rozporządzenie Ministra Rolnictwa i Rozwoju Wsi z dnia 22 maja 2013 roku w sprawie zastosowań małoobszarowych środka ochrony roślin. Dziennik Ustaw Rzeczypospolitej Polskiej, Warszawa, dnia 7 czerwca 2013 r. poz. 659.

Stajszczak A. 2011. Wpływ globalizacji i prawa europejskiego na rynek środków ochrony roślin w Polsce. Zesz. Nauk. SGGW Warszawa - Problemy Rolnictwa Światowego 11 (26): 106-115.

Thomas G.J., Sweetingham M.W. 2003. Fungicide seed treatment reduce seed transmission and severity of lupin anthracnose caused by Colletotrichum gloeosporioides. Austral. Plant Pathol. 32: 39-46. 